\title{
Evaluation of the Utilization of Catheter Associated Urinary Tract Infection Bundle Among Critical Care Nurses - Kenyatta National Hospital
}

\author{
Assanga P. A. ${ }^{1,2,}$, Omondi A. L. ${ }^{1}$, Inyama H. K. ${ }^{1}$ \\ ${ }^{1}$ School of Nursing Sciences, University of Nairobi, Nairobi, Kenya \\ ${ }^{2}$ Social Services League Hospital, Critical Care Unit, Nairobi, Kenya
}

\section{Email address:}

ppamessa@yahoo.com (Assanga P. A.), laomondi@uonbi.ac.ke (Omondi L. A.), hannahinyama@gmail.com (Inyama H. K.)

${ }^{*}$ Corresponding author

\section{To cite this article:}

Assanga P. A., Omondi L. A., Inyama H. K. Evaluation of the Utilization of Catheter Associated Urinary Tract Infection Bundle among Critical Care Nurses - Kenyatta National Hospital. American Journal of Nursing Science. Vol. 5, No. 5, 2016, pp. $201-212$. doi: 10.11648/j.ajns.20160505.15

Received: September 2, 2016; Accepted: September 18, 2016; Published: October 19, 2016

\begin{abstract}
Majority if not all patients admitted to the Critical Care Units (CCUs) have indwelling urinary catheters predisposing them to Catheter Associated Urinary Tract Infections (CAUTI). CAUTI bundle was introduced to reduce the infections whose prevalence had been high. Utilization of this bundle is considered standard gold and should be utilized completely by nurses while providing care to the patients. The aim of this study was to determine the utilization of the CAUTI bundle among critical care nurses at Kenyatta National Hospital's (KNH's). The study applied a cross-sectional descriptive design with cluster sampling and simple random sampling for each cluster. Ninety five critical care nurses were selected from a total of 136 nurses using Cochran's formulae. A structured questionnaire and an observation checklist were used to collect data which was analyzed using the Statistical Package for Social Sciences (SPSS) version 21.0. Descriptive statistics was used to summarize the data and inferential statistics (Chi-square test, odds ratio and Pearsons' correlation) was used to establish relationships between variables. Nurses working at KNH's CCUs utilized and adhered (49.5\%; P $>0.005)$ to the bundle. There was a weak correlation between the observed and reported bundle utilization $[\mathrm{r}=0.043 ; 95 \% \mathrm{CI} 0.16-0.24 ; \mathrm{P}=0.678]$.
\end{abstract}

Keywords: Catheter Associated Urinary Tract Infection (CAUTI), Critical Care Units (CCUs), Kenyatta National Hospital (KNH), Critical Care Nurses, Centre of Disease Control (CDC)

\section{Introduction}

\subsection{Background Information}

More than $75 \%$ of urinary tract infections are associated with indwelling urinary catheters [1]. Patients admitted to the CCUs have indwelling urinary catheters that stay for long predisposing them to CAUTIs. Catheter Associated Urinary Tract Infections increase morbidity, mortality and hospital stay and cost [2]. The focus on prevention of CAUTI was developed in 2009 when the CDC developed guidelines that were later bundled into multi-modal sets of interventions using scientific evidences [3-4]. The development of the bundle was due to high mortality rate and prevalence of CAUTI in the CCUs [5]. The care bundles have elements of which each has scientific evidence. There should be adherence and utilization of all the elements to every catheterized patient $100 \%$ of the time [6]. Nurses are charged with the responsibility of catheter care making them accountable for the utilization of the bundle. A study was conducted in Turkey on multidimensional infection control approaches on CAUTI and the findings showed a reduction in CAUTI rates with the utilization of the prevention bundle [7]. Any ideal CCU would need to consider improvement in patient care a priority by utilizing the bundle. Although many studies have been conducted in this aspect of patient care the prevalence rate of CAUTI still remains high. 


\subsection{Statement of the Problem}

Catheter associated urinary tract infections (CAUTI) comprise of 30 to $40 \%$ of all the Hospital Acquired Infections (HAIs) occurring in the acute care hospitals [8]. There is an estimated 1 million CAUTIs per year worldwide associated with additional cost per admission when complicated by bloodstream infections at $\$ 400$ million [9]. The prevalence rate of CAUTI in the CCU settings is 2.4 to 35 infections per 1000 catheter days worldwide [1]. That of the developed countries is 3.3 to 17.4 infections per 1000 catheter days while in the developing countries is at 9.9 to 35 infections per 1000 catheter days. At $\mathrm{KNH}$, the incidence rate is $32 \%$ with that of the CCUs being $18 \%$ [10-11]. This high prevalence of CAUTI at KNH poses a greater challenge to the hospital safety and quality health care of the patients at $\mathrm{KNH}$ which is the largest teaching and referral hospital in East Africa. Hence the need to conduct this study since nurses do provide direct care to patients and they are responsible and accountable for the utilization of this bundle. 17 to $69 \%$ of CAUTIs can be prevented with reduction in the prevalence by good utilization and adherence to the bundle [8].

\subsection{Justification}

There is a high indication for the use of indwelling urinary catheters among patients admitted in the CCUs. These patients stay for long, are bedridden and most are unconscious hence need for catheterization. These catheters are indicated for therapeutic uses being hourly urine monitoring \& monitoring of the hemodynamic status and to providing comfort to the patients who in most cases are not able to take care of their elimination. These patients are at a high risk of developing CAUTI. Due to the nature of their illness and are immunocompromised. CAUTIs compromise on bed occupancy which is $100 \%$ in the CCUs at $\mathrm{KNH}$. CAUTI bundle was introduced to help in reducing the rate of CAUTI worldwide and nurses are responsible and accountable for the utilization and adherence to the bundle while caring for catheterized patients.

Specific HAIs have stopped being reimbursed in the United States of America (USA) by insurance companies since 2008 [12-13], which could be effected by insurance companies in Kenya. The impact of CAUTIs can take many years post discharge from the hospital whereby these patients can develop urethral strictures. Despite evidence based researches being conducted on prevention of CAUTIs, the incidence rates still remain high. Currently there is no evidence of studies conducted in Kenya on utilization of the CAUTI bundle. This necessitated the need to conduct a scientific study in this area of patient care.

\subsection{Objectives}

The broad objective was to determine the utilization of the catheter associated urinary tract infection bundle among nurses working at Kenyatta National Hospital's critical care units.
The specific objectives were:

a) To evaluate the utilization of the CAUTI bundle elements by nurses working at KNH's CCUs.

b) To assess the adherence of nurses to CAUTI bundle elements at KNH's CCUs.

c) To correlate the observed with the reported practices of CAUTI bundle element utilization by critical care nurses at KNH's CCUs.

\section{Literature Review}

\subsection{Utilization of the CAUTI Bundle}

A care bundle is a group of evidence based practice interventions that when grouped and used together reduce infections and improve patient outcome. In day to day clinical practice, these actions and interventions may not always all be done consistently [5, 14-15]. To utilize the CAUTI bundle, the nurses should be knowledgeable of the bundle's existence and the current evidence based practices. Lack of knowledge on the bundle within the CCUs affects the ability of nurses to utilize and adhere to it. A nonrandomized control trial study conducted in 13 CCUs in Turkey had findings of reduction in CAUTI rates when the nurses were educated and became knowledgeable on the CAUTI bundle [7]. There were inconsistencies in the nurses' knowledge regarding maintenance of indwelling urinary catheters in another study on the bundle. After reeducation and training in this study, there was modest decrease in the number of inconsistencies in patient care making it evident that lack of knowledge impeded on the effectiveness of nurses in preventing CAUTIs [16]. Enhancing nursing knowledge is important to a healthcare institution provides quality care that is safe [17]. There is lack of translating knowledge into practice hence, the need to this understanding [18].

The American Association of Critical-Care Nurses (ACCN) stated that CAUTI is a nurse sensitive indicator. Training and education of nurses on evidence based practices and guidelines have impact on decreasing CAUTI rates. Catheter Associated Urinary Tract Infections (CAUTIs) are associated with serious infections such as sepsis, acute pyelonephritis and other adverse outcomes such as prolonged hospital stay, increased morbidity and mortality [19]. A study conducted in the USA, where by a hospital completely revamped its policies and procedures related to the use and maintenance of urinary catheters. This resulted in 548 fewer CAUTIs in the year after intervention compared with the year preceding the intervention [20]. Nurses require education on indwelling urinary catheter maintenance to adequately utilize the bundle.

\subsection{Nursing Practice on Utilization and Adherence to CAUTI Bundle}

The presence of a urethral catheter predisposes patients to CAUTI by provoking inflammation and traumatizing the mucosa of the urethra and bladder neck. Inflammation and 
mechanical damage to the urinary epithelium not only increases the risk of UTI but also compromises the patient's ability to mount an effective immune response to bacteria in the bladder. Catheter care is completed primarily by the nursing staff hence the importance of prevention of CAUTI by use of the bundle [21].

The practices on the CAUTI prevention based on the elements of the maintenance care bundle include maintenance of a closed drainage system, proper hand hygiene, daily meatal care, maintenance of an unobstructed urinary flow, emptying of the drainage bag with a clean and separate container for each patient, drainage bag maintenance and securing the urinary catheter to the thigh or abdomen. Utilization of this bundle reduces CAUTI, improves catheter care practices and spares hospitals millions of dollars [22]. Increased adherence to the recommended CAUTI preventive practices has been shown to reduce the incidence of CAUTI in the CCU.

A study conducted on implementation and adherence to the maintenance bundle had findings of a significantly strong negative relationship between improvement in the rate of catheter maintenance bundle elements adherence and the CAUTI prevalence rates. CAUTI rates decreased from 107.4 to 29.54 infections per 1000 catheter days [23]. A similar study conducted in a rural hospital in Egypt had findings of reduction in the rate of CAUTI from 90.12 to 65.69 infections per 1000 catheter days on implementation and adherence to the CAUTI bundle elements. There was also an increase in the adherence to the maintenance bundle from 40 to $70 \%$ in this study. Utilization and adherence to the recommended CAUTI bundle should become part of patient safety worldwide. Preventing bacteria from gaining access to the internal surface of the drainage system or urine is facilitated by always keeping the system closed, avoiding catheter manipulation with unclean and ungloved hands and draining the system into a clean container that has not been used for other patients.

Hand hygiene is acknowledged as a crucial component of effective infection prevention. Proper performance of hand hygiene at key moments during patient care is important. This ensures safety for the patient receiving care and for subsequent patients the nurse interacts with decreasing the risk of infection transmission to the population and themselves [24]. Multiple studies have shown that hand hygiene is the primary intervention in preventing transmission of microorganisms. While clean handling of catheters is important, routine meatal cleaning is necessary. Nurses must provide meatal care and hygiene at least twice daily or as needed for a patient with an indwelling urinary catheter. Soap and water are effective in reducing the number of organisms around the urethra.

Maintaining a closed urinary drainage system is important in infection control since a break in the system can lead to introduction of microorganisms. Bacteria are usually introduced when the closed drainage system is opened leading to internal or intraluminal accession of microorganisms increasing the risk of CAUTI development.
The nurse has the responsibility of monitoring the patency of the system to prevent pooling of urine within the tubing. Urine in the drainage bag is an excellent medium for microorganism growth. Every effort must be made to prevent microorganisms from gaining entry into the indwelling urinary catheter, drainage system and bladder during catheter maintenance activities. Bacteria can travel up the drainage tubing to grow in pools of urine that can easily backflow to the bladder [12]. Measures should be taken to maintain unobstructed urinary flow by keeping the catheter and collecting tube free from kinking [8, 25]. Retrograde bacterial migration from the urine drainage bag outlet tube is a major source of bacterial contamination. A study by Maki et al found that not allowing the drainage tubing to drop lower than the drainage bag was associated with a significant increased risk of CAUTI [26]. Drainage bags should be hanged on the end of the bed with the tubing in a straight line, avoiding looping or kinking to promote unobstructed urine flow. The drainage bag should be positioned below the level of the bladder to utilize gravity hence facilitating drainage. Correct positioning of the tubing should be by the use of a securement device or tape to facilitate drainage into the bag and prevent reflux of old urine into the bladder as reflux and stagnation contributes to CAUTI [27]. It has been demonstrated that the use of a securement device to prevent movement of the catheter as the patient moves as well as keeping the drainage bag below the level of the bladder are effective in reducing CAUTI rates by $70 \%$ [25]. All urinary catheters should be secured, yet securement is not routinely performed in practice. The CDC guidelines and standards have been put in place to ensure that catheters are secured to the thigh or abdomen [28]. Unsecured urinary catheters can lead to bleeding, trauma, pressure sores around the meatus and bladder spasms from pressure and traction [29]. The healthcare infection control practices advisory committee's 2009 guidelines provide recommendations that urinary drainage bags should be emptied frequently enough to maintain urine flow and prevent reflux [30]. The drainage bag should be emptied regularly as a separate procedure into a clean container for each patient. While emptying the drainage bag, the nurses should avoid splashing the urine and ensure that the drainage spigot does not come into contact with the non-sterile collecting container [31]. Urine collection containers should be disinfected after each use. The drainage bag should be emptied when half to two thirds full to avoid traction on the catheter from the weight of the drainage bag [32].

Assessment and auditing of adherence to all elements of the bundle should be done using a simple "yes" or "no" for each of the elements of the bundle. If all elements have been accomplished or an element was contraindicated, the bundle is counted as complete. If any of the elements are absent, the bundle is incomplete since there is no partial credit. The goal of adherence to the bundles should be at $95 \%$ or greater since it's measured as either $100 \%$ or $0 \%$. To achieve $100 \%$ all the elements of the bundle must be implemented. This focuses attention on the importance of delivering all elements. Care 
bundle adherence allows measurement of target improvements and demonstrates adherence against key practices hence improving patient care. The bundle is considered to be adhered to when all the elements of the bundle are utilized and that which is contraindicated be fully documented. If all elements have been accomplished with the exception of what is contraindicated, the bundle is counted as complete [15].

\subsection{Theoretical Framework}

This research adopted the Donabedian's model of healthcare. This model allows for conceptualization of the underlying mechanisms that may contribute to poor quality of care in patients. The model was developed to assess the quality of care in clinical practice and is composed of three categories which are the structure, process and outcome. Each of the categories represents information that may be collected to draw inferences about the quality of care in a given system. It is a useful framework for quality assessment of healthcare services and evaluating the quality of healthcare provided since improvement in the structure of care should lead to improvements in clinical processes that should in turn improve patient outcome [33]. Structure is composed of the settings where care is delivered that is, staff credentials, ratios \& training, facility operating capacities, environment, hospital buildings, financing and equipment. Healthcare institutions should ensure that those who take care of the catheterized patients especially the nurses are trained and competent in the utilization of the CAUTI bundle. Process is the transactions between patients and health care providers. This reflects the procedures such as maintenance of indwelling urinary catheters and captures the timeliness and accuracy in diagnosis and prevention of complications such as CAUTI. While applying the process, information is obtained from medical records, interviews with patients and practitioners or direct observations of healthcare delivery procedures and skills. The nurses should be audited frequently on utilization of the CAUTI bundle. There should be protocols to guide prevention of CAUTI. The process also measures the quality of care given to the patients. Outcome is the effect of healthcare on the health status which includes the changes in individuals and population such as morbidity, mortality, hospital stay and additional costs. The outcome tracks the desired states resulting from care processes as effects of healthcare on patients. The nurses should ensure that they utilize the CAUTI bundle so as to reduce or eliminate the occurrence of CAUTI [33].

\section{Methodology}

This was a descriptive cross-sectional research design. This was used since the study period was two months. Quantitative research method was used for data collection which consisted of structured questionnaires and observation checklist. A sample of 95 nurses was used which was determined using the Cochran's formulae from a total population of 136 from the off duty roster. Cluster sampling was used to select the required sample and the clusters consisted of the main, cardiothoracic, neurosurgical and acute care CCUs. Simple random sampling was then used to select the required sample from each cluster. The study population consisted of the nurses who were on permanent employment on permanent and were working within the CCUs, consented and were available to participate in the study.

Data was collected using administered structured questionnaires to collect data on knowledge on the bundle and the reported level of utilization of the CAUTI bundle. The questions were in the form of closed ended and Likert scale with specific focus on the nurses' socio-demographic data, practices and utilization of the CAUTI bundle within the units. The questions also explored the various challenges that nurses faced on utilization of the bundle. Observation checklist was also used to identify the observed utilization of the bundle elements. This data was collected by participant observation. The approach was based on a 'yes' or 'no' answer on the specific bundle elements that is maintaining an intact tamper evident seal, securing the catheter, hand hygiene, daily meatal care with soap and water, empting the urinary drainage bag with a clean and separate container, ensuring that the drainage bag is not overfilled, urinary drainage bag not touching the floor and maintaining an unobstructed urinary flow. The observation was done three times as the participants cared for patients. The observation checklist was adopted and modified from the Comprehensive Unit based Safety Program (CUSP): Stop CAUTI Supplement [19].

The study was approved by Kenyatta National Hospital/University of Nairobi Research and Ethics Committee (KNH/UON ERC). Clearance to conduct research was sought from $\mathrm{KNH}$ authorities. Those who were eligible to participate in the study were explained to the aim of the study, the study procedure and consent obtained. This was done on a voluntary basis from those who were eligible. Data collection was done upon obtaining consent. The study participants were first observed as they rendered care to the catheterized patients related to the utilization of the CAUTI bundle. The observation was structured whereby an observation checklist was used with specific variables derived from the elements of the CAUTI maintenance bundle. The study participants were observed at three different times during their shifts and the researcher took part in the care of the patients during the study period. An average of the observations was then calculated to determine the actual utilization of the bundle. Out of the three observations those who performed the elements twice and above were rated to be utilizing it while the ones who just utilized it once out of the three observations were rated not to be utilizing it. This helped to prevent the bias of one time observation that would occur due to change of practice with the presence of an observer and the Hawthorne effect. Then the structured questionnaires were administered to the study participants to fill. Guidance was given whenever it was required while filling in the questionnaires. The data collected was then counterchecked for complete entry, coded, edited for accuracy. Upon completing the 
questionnaires, they were coded and the researcher checked that they were completely filled while the areas not complete were completed by the participants before the data collection questionnaires were stored. All the raw data was stored in box files which were kept under key and lock and in firewall and password protected computers and analyzed using SPSS version 21.

\section{Results}

\subsection{Socio-demographic Characteristics}

\subsubsection{Gender, Age, Level of Education, Specialty Training}

$71 \%$ (67) were females with males being 29\% (28). The age distribution was; $42.1 \%$ (40) were 30 to 39 years, $34.7 \%$ (33) were 40 to 49 years, $17.9 \%$ (17) were 20 to 29 years and $5.3 \%$ (5) were 50 to 59 years. Higher diploma holders were $53.7 \%$ (51), diploma holders were 22.1\% (21), Bachelor's degree holders were $23.2 \%$ (22) and Master in nursing degree holders were $1.1 \%$ (1). The participants who had critical care nursing training were $70 \%(68), 22 \%(21)$ had accident and emergency training and $6 \%$ (6) did not have any specialty training. Table 1 illustrates findings of the socio-demographic characteristics of the participants.

Table 1. Socio-demographic Characteristics.

\begin{tabular}{lll}
\hline Characteristic & Frequency (n) & Percentage (\%) \\
\hline Gender & 28 & 29 \\
Male & $\mathbf{6 7}$ & $\mathbf{7 1}$ \\
Female & & \\
Age in years & 17 & 17.9 \\
$20-29$ & $\mathbf{4 0}$ & $\mathbf{4 2 . 1}$ \\
$\mathbf{3 0}-\mathbf{3 9}$ & 33 & 34.7 \\
$40-49$ & 5 & 5.3 \\
$50-59$ & 0 & 0 \\
Above 60 & mode 37.7 and standard deviation 7.5. \\
The mean age was 37.2, median 37.6, & \\
Level of Education & 21 & 22.1 \\
Diploma & $\mathbf{5 1}$ & $\mathbf{5 3 . 6}$ \\
Higher Diploma & 22 & 23.2 \\
Degree & 1 & 1.1 \\
Masters & & \\
Specialty Training & $\mathbf{6 8}$ & $\mathbf{7 2}$ \\
Critical Care Nursing & 21 & 22 \\
Accident and Emergency Nursing & 6 & 6 \\
None & & \\
\hline
\end{tabular}

\subsubsection{Years of Experience}

The participants who had 1 to 5 years of experience were
$34.7 \%$ (35), $31.6 \%$ (30) had 6 to 10 years' experience, $16.8 \%$ (16) had more than 10 years' experience while $14.7 \%$ (14) had less than one year of experience in the critical care unit as shown in Figure 1.

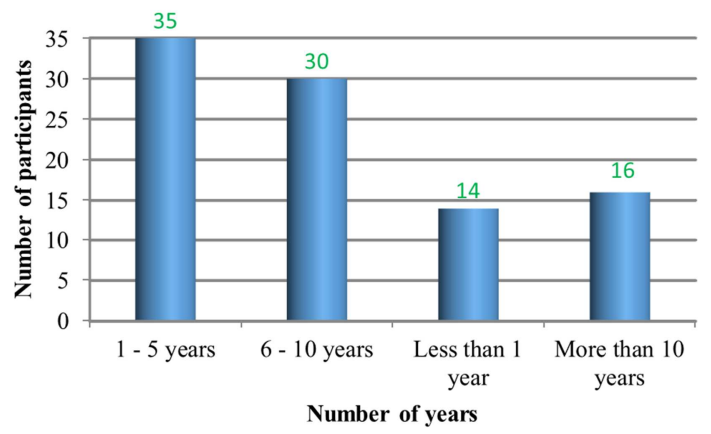

Figure 1. Years of experience.

\subsubsection{Cadre}

$35 \%$ (33) were Senior Nursing Officers (SNO), Nursing Officer II (NOII) were 31\% (30), Nursing Officer III (NOIII) were $18 \%$ (17) and Nursing Officer I (NOI) were 16\% (15) as shown in Figure 2.

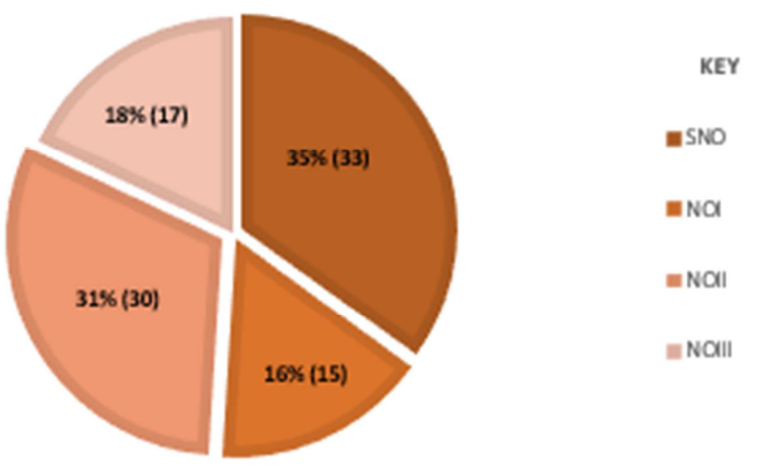

Figure 2. Participants' Cadre.

\subsection{Utilization of CAUTI Bundle}

\subsubsection{Knowledge on CAUTI Bundle} General knowledge on the bundle

$43(55.8 \%)$ of the participants knew about the CAUTI bundle and $48.4 \%$ (46) had knowledge on the elements of the bundle. $43(45.3 \%)$ reported to be utilizing the CAUTI care bundle while $81.1 \%(77)$ reported that they were not audited on the utilization of the bundle as shown in Table 2.

Table 2. General knowledge on the bundle.

\begin{tabular}{|c|c|c|c|}
\hline Statement & Response & Frequency (n) & Percentage (\%) \\
\hline \multirow{2}{*}{ Knowledge on the CAUTI bundle } & Yes & 53 & 55.8 \\
\hline & No & 42 & 44.2 \\
\hline \multirow{2}{*}{ Aware of the elements of the CAUTI care bundle } & Yes & 46 & 48.4 \\
\hline & No & 49 & 51.6 \\
\hline \multirow{2}{*}{ Utilize the CAUTI prevention care bundle in your unit } & Yes & 43 & 45.3 \\
\hline & No & 52 & 54.7 \\
\hline \multirow{2}{*}{ Audited on the utilization of the CAUTI bundle } & Yes & 18 & 18.9 \\
\hline & No & 77 & 81.1 \\
\hline
\end{tabular}




\section{Knowledge on emptying of the urine drainage bag}

The participants were asked the extent to which they agreed with emptying of the urine drainage bag should on a five Likert scale as shown in Table 3.

Table 3. Emptying of the urine drainage bag.

\begin{tabular}{|c|c|c|c|c|c|}
\hline Emptying of the urine drainage bag & SA \% (n) & A \% (n) & U \% (n) & D \% (n) & SD \% (n) \\
\hline When full & $30.5(29)$ & $17.9(17)$ & $4.2(4)$ & $24.2(23)$ & $23.2(22)$ \\
\hline When half full & $13.7(13)$ & $32.6(31)$ & $10.5(10)$ & $27.4(26)$ & $15.8(15)$ \\
\hline At the end of the shift & $31.6(30)$ & $26.3(25)$ & $2.1(2)$ & $21.1(20)$ & $18.9(18)$ \\
\hline
\end{tabular}

Key: SA - Strongly Agree, A - Agree, U - Undecided, D - Disagree, SD - Strongly Disagree

\section{Knowledge on utilization of the CAUTI bundle}

Participants were asked to state the extent to which they agreed with the listed practices on the bundle utilization on a five Likert scale and the responses were as shown in Table 4.

Table 4. Knowledge on utilization of the CAUTI bundle.

\begin{tabular}{|c|c|c|c|c|c|}
\hline \multirow{2}{*}{ Practice on maintenance bundle } & \multicolumn{5}{|l|}{ Responses } \\
\hline & SA \% (n) & A \% (n) & $\mathbf{U} \%(\mathbf{n})$ & D \% (n) & SD \% (n) \\
\hline Hand hygiene should be performed for every patient contact & $91.6(87)$ & $8.4(8)$ & $0(0)$ & $0(0)$ & $0(0)$ \\
\hline A closed drainage system should be maintained always & $84.2(84)$ & $14.7(21)$ & $1.1(1)$ & $0(0)$ & $0(0)$ \\
\hline Drainage bag should be emptied using a clean and separate container for each patient & $72.6(69)$ & $22.1(21)$ & $2.1(2)$ & $3.2(3)$ & $0(0)$ \\
\hline Drainage bag should not touch the floor or surfaces & $87.4(83)$ & $11.6(11)$ & $0(0)$ & $1.1(1)$ & $0(0)$ \\
\hline Indwelling urinary catheters should be secured & $71.6(68)$ & $26.3(25)$ & $2.1(2)$ & $0(0)$ & $0(0)$ \\
\hline There should be initiatives on reminding colleagues and doctors on catheter removal & $71.6(68)$ & $28.4(27)$ & $0(0)$ & $0(0)$ & $0(0)$ \\
\hline CCU's should have daily checklists for CAUTI maintenance bundle & $69.5(66)$ & $29.5(28)$ & $1.1(1)$ & $0(0)$ & $0(0)$ \\
\hline
\end{tabular}

Key: SA - Strongly Agree, A - Agree, U - Undecided, D - Disagree, SD - Strongly Disagree

\subsubsection{Utilization of the CAUTI Bundle \\ Reported utilization of the CAUTI bundle}

The participants were asked to respond to "yes" for the performed or "no" for not performed practices regarding the utilization of the CAUTI bundle. The responses are as shown in Table 5. With the exception of maintaining an intact tamper evident seal that was at $58.9 \%$ (56) reported to utilization, all the others were reported to be utilized by more than $80 \%$ (76) of the participants as shown in Table 5 .

Table 5. Reported Utilization of the CAUTI Bundle.

\begin{tabular}{|c|c|c|}
\hline Bundle Element & Yes \% (n) & No \% (n) \\
\hline Maintaining the tamper evident seal intact & $58.9(56)$ & $41.1(39)$ \\
\hline Securing the catheter & $85.3(81)$ & $14.7(14)$ \\
\hline Hand hygiene with every patient contact & $92.6(88)$ & $7.4(7)$ \\
\hline Daily meatal care & 84.2(80) & $15.8(15)$ \\
\hline Emptying the drainage bag with a clean container & 88.4(84) & $11.6(11)$ \\
\hline Ensuring that the drainage bag is not overfilled & $90.5(86)$ & $9.5(9)$ \\
\hline Maintaining an unobstructed urinary flow & 93.7(89) & $6.3(6)$ \\
\hline
\end{tabular}

\section{Observed utilization of the CAUTI bundle}

The participants were observed using an observation checklist as they rendered care to the patients based on the utilization of the bundle. Three observations were made to ascertain the actual practice on the elements. Average observation for each and every element was then calculated. This was based on three observations of which if a participant was observed to be utilizing the element two times out of the three observations, then the individual got a yes and vice versa. It was observed that most of the participants did not practice the reported elements apart from $93 \%$ (88) who ensured that the urine drainage bags were not touching the floor and $82.1 \%$ (78) who ensured that the urine drainage bags were not overfilled while $100 \%$ (95) maintained an intact tamper evident seal. It was also noted that only $2.1 \%$ (2) had secured the patients' catheters and $22.1 \%$ (21) performed hand hygiene with every patient contact as shown in Table 6. 
Table 6. Observed Utilization of the Bundle.

\begin{tabular}{|c|c|c|c|c|c|}
\hline \multirow{2}{*}{ Bundle Element } & \multirow{2}{*}{ Response } & \multicolumn{3}{|c|}{ Episodes of encounter } & \multirow{2}{*}{ Average \% (n) } \\
\hline & & $1^{\text {st }} \%$ (n) & $2^{\text {nd }} \%(n)$ & $3^{\text {rd } \%(n)}$ & \\
\hline \multirow{2}{*}{ Maintaining the tamper evident seal intact } & Yes & $100(95)$ & $100(95)$ & $100(95)$ & $100(95)$ \\
\hline & No & $0(0)$ & $0(0)$ & $0(0)$ & $0(0)$ \\
\hline \multirow{2}{*}{ Securing the catheter } & Yes & $97.8(93)$ & $2.2(2)$ & $2.2(2)$ & $2.1(2)$ \\
\hline & No & $2.2(2)$ & 97.8 (93) & 97.8 (93) & $97.8(93)$ \\
\hline \multirow{2}{*}{ Hand hygiene with every patient contact } & Yes & $41.1(39)$ & $11.6(11)$ & $13.7(13)$ & $22.1(21)$ \\
\hline & No & $58.9(56)$ & $88.4(84)$ & $86.3(82)$ & 77.9 (93) \\
\hline \multirow{2}{*}{ Daily meatal care } & Yes & $91.6(87)$ & $6.3(6)$ & $7.4(7)$ & $35.1(33)$ \\
\hline & No & $8.4(8)$ & $93.7(89)$ & $92.6(93)$ & $64.9(62)$ \\
\hline \multirow{2}{*}{ Emptying the drainage bag with a clean container } & Yes & $34.7(33)$ & $8.4(8)$ & $9.5(9)$ & $17.5(17)$ \\
\hline & No & $65.3(62)$ & $91.6(87)$ & $90.5(86)$ & $82.5(78)$ \\
\hline \multirow{2}{*}{ Ensuring that the drainage bag is not overfilled } & Yes & $98.9(94)$ & $80.0(76)$ & $67.4(64)$ & $82.1(78)$ \\
\hline & No & $1.1(1)$ & $20.0(19)$ & $32.6(31)$ & $17.9(22)$ \\
\hline \multirow{2}{*}{ Ensuring that the drainage bag is not touching the floor } & Yes & $93.7(89)$ & $92.6(88)$ & $92.6(88)$ & $93(88)$ \\
\hline & No & $6.3(6)$ & $7.4(7)$ & $7.4(7)$ & $7(7)$ \\
\hline \multirow{2}{*}{ Maintaining an unobstructed urinary flow } & Yes & $51.6(49)$ & $38.9(37)$ & $42.1(40)$ & $44.2(42)$ \\
\hline & No & $48.4(46)$ & $61.1(58)$ & $57.9(55)$ & $55.8(53)$ \\
\hline
\end{tabular}

\section{Meatal care}

The participants were asked how often they performed meatal care. 64 (67.4\%) of the respondents reported to be performing meatal care with every care and when the patient had incontinence. However, $27.4 \%$ (26) reported to be performing meatal care once per shift with 5.3\% (5) not performing meatal care as shown in Figure 3.

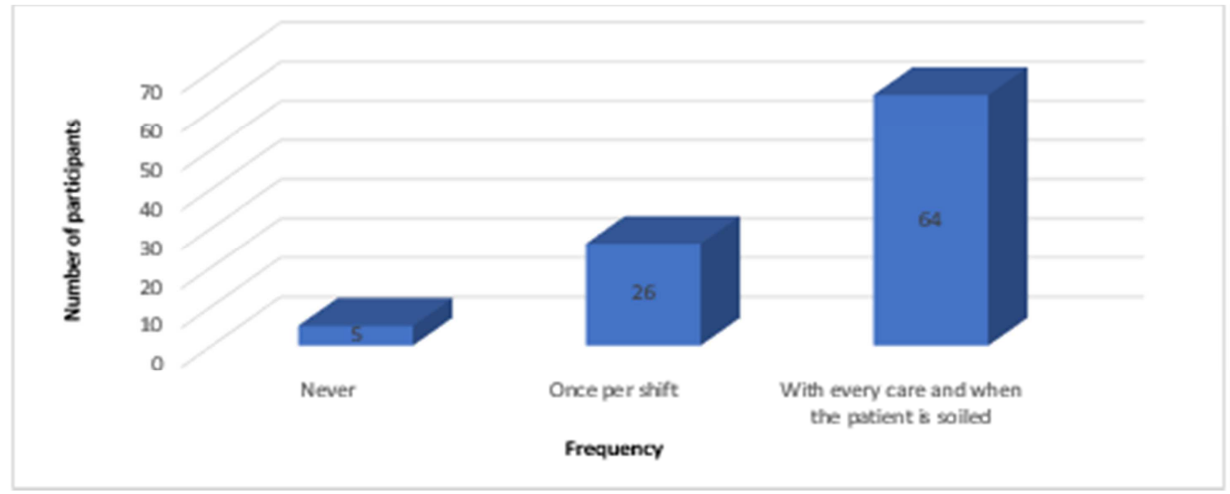

Figure 3. Meatal care frequency.

\section{Solution used for meatal care}

$43(45 \%)$ of the respondents reported to be using antiseptic solution, 28\% (27) used plain water and 27\% (25) used soap and water as shown in Figure 4.

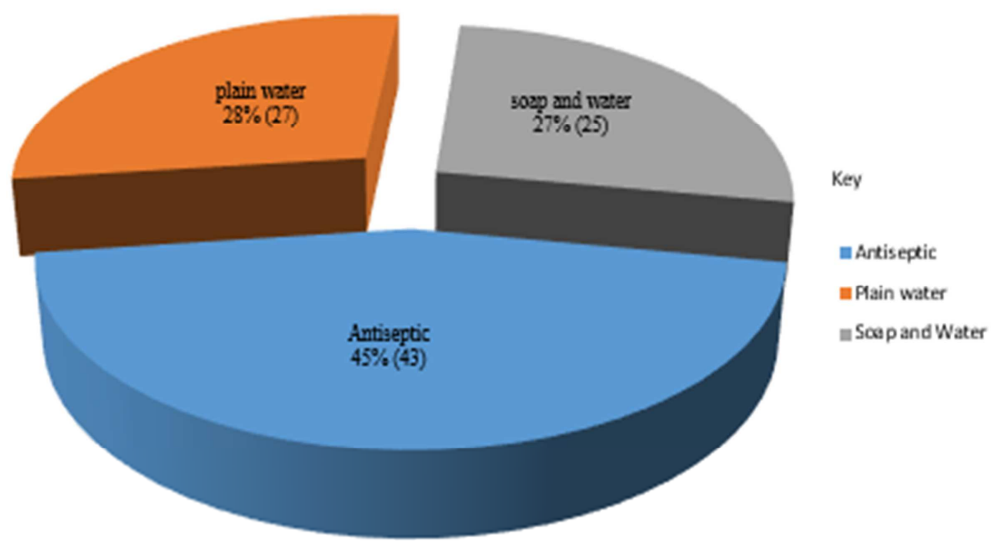

Figure 4. Solution used for meatal care. 


\subsection{Adherence to the CAUTI Bundle}

\subsubsection{Comparison Between the Reported and Observed Bundle Utilization}

$80 \%$ (76) of the participants reported to be utilizing the bundle elements. This was compared to what was actually practiced and there was a difference since most of the elements were not performed as required compared to the reported values as shown in Table 7.

Table 7. Cross tabulation of observed and reported bundle utilization.

\begin{tabular}{|c|c|c|c|}
\hline Bundle Element & Response & Reported Practices \%(n) & Observed practices \%(n) \\
\hline \multirow{2}{*}{ Maintaining an intact tamper evident seal } & Yes & $58.9(56)$ & $100(95)$ \\
\hline & No & 41.1(39) & $0(0)$ \\
\hline \multirow{2}{*}{ Securing the catheter } & Yes & $85.3(81)$ & $2.1(2)$ \\
\hline & No & $14.7(14)$ & $97.8(93)$ \\
\hline \multirow{2}{*}{ Hand hygiene with every patient contact } & Yes & $92.6(88)$ & $22.1(21)$ \\
\hline & No & $7.4(7)$ & $77.9(93)$ \\
\hline \multirow{2}{*}{ Daily meatal care } & Yes & $84.2(80)$ & $35.1(33)$ \\
\hline & No & $15.8(15)$ & $64.9(62)$ \\
\hline \multirow{2}{*}{ Emptying the drainage bag with a clean container } & Yes & $88.4(84)$ & $17.5(17)$ \\
\hline & No & $11.6(11)$ & $82.5(78)$ \\
\hline \multirow{2}{*}{ Ensuring that the drainage bag is not overfilled } & Yes & $90.5(86)$ & $82.1(78)$ \\
\hline & No & $9.5(9)$ & $17.9(22)$ \\
\hline \multirow{2}{*}{ Ensuring that the drainage bag is not touching the floor } & Yes & $96.8(92)$ & $93(88)$ \\
\hline & No & $3.2(3)$ & $7(7)$ \\
\hline \multirow{2}{*}{ Maintaining an unobstructed urinary flow } & Yes & $93.7(89)$ & $44.2(42)$ \\
\hline & No & $6.3(6)$ & $55.8(53)$ \\
\hline
\end{tabular}

\subsubsection{Relationship Between Demographic Characteristics and Bundle Utilization}

Odds ratio was done to determine the association between the demographic characteristics and bundle utilization. There was no significant association between the utilization of the bundle and the respondents' demographic characteristics $(\mathrm{P}>0.05)$ as shown in Table 8.

Table 8. Relationship between the demographic characteristics and bundle utilization.

\begin{tabular}{|c|c|c|c|c|c|c|c|}
\hline \multirow[b]{2}{*}{ Characteristic } & \multicolumn{2}{|c|}{ Utilization of CAUTI bundle } & \multirow{2}{*}{ OR } & \multicolumn{2}{|c|}{$95 \%$ CI } & \multirow{2}{*}{$X^{2}$ value (df) } & \multirow{2}{*}{$\mathrm{X}^{2}$ Test (p-value) } \\
\hline & Yes & No & & L.L & U.L & & \\
\hline \multicolumn{8}{|l|}{ Age in years } \\
\hline $20-29$ & $7(41.2)$ & $10(58.8)$ & 1.0 & & & $0.32(3)$ & 0.957 \\
\hline $30-39$ & $19(47.5)$ & $21(52.5)$ & 1.29 & 0.36 & 4.86 & & \\
\hline $40-49$ & $14(42.4)$ & $19(57.6)$ & 1.05 & 0.28 & 4.14 & & \\
\hline $50-59$ & $2(40)$ & $3(60)$ & 0.95 & 0.1 & 10.85 & & \\
\hline \multicolumn{8}{|l|}{ Gender } \\
\hline Male & $11(39.3)$ & $17(60.7)$ & 1.0 & & & $0.39(1)$ & 0.532 \\
\hline Female & $31(46.3)$ & $36(53.7)$ & 1.33 & 0.5 & 3.65 & & \\
\hline \multicolumn{8}{|l|}{ Specialty in nursing } \\
\hline Critical Care & $9(42.9)$ & $12(57.1)$ & 1.0 & & & $0.1(2)$ & 0.952 \\
\hline Accident and Emergency & $30(44.1)$ & $38(55.9)$ & 1.05 & 0.35 & 3.24 & & \\
\hline None & $3(50)$ & $3(50)$ & 1.33 & 0.14 & 12.4 & & \\
\hline \multicolumn{8}{|l|}{ Years of experience } \\
\hline Less than 1 & $3(21.4)$ & $11(78.6)$ & 1.0 & & & $6.48(3)$ & 0.09 \\
\hline $1-5$ & $20(57.1)$ & 15 (42.9) & 4.89 & 1.0 & 31.1 & & \\
\hline $6-10$ & $14(46.7)$ & $16(53.3)$ & 3.21 & 0.64 & 21 & & \\
\hline$>10$ & $5(31.3)$ & $11(68.8)$ & 1.67 & 0.24 & 13.2 & & \\
\hline \multicolumn{8}{|l|}{ Cadre } \\
\hline NOIII & $7(41.2)$ & $10(58.8)$ & 1.0 & & & $2.97(3)$ & 0.397 \\
\hline NOII & $16(53.3)$ & 14 (46.7) & 1.63 & 0.42 & 6.5 & & \\
\hline NOI & $4(26.7)$ & $11(73.3)$ & 0.52 & 0.1 & 2.88 & & \\
\hline SNO & $15(45.5)$ & $18(54.6)$ & 1.52 & 0.4 & 7.0 & & \\
\hline
\end{tabular}

Key: LL - Lower Limit, UP - Upper Limit, OR - Odds Ratio, df - degree of freedom

\subsubsection{Relationship Between Utilization and Knowledge on the Bundle}

The participants who had knowledge on the bundle utilized it 24.1 times more than those who did not [OR 24.1; 95\% CI 6.7104; $\mathrm{P}<0.01]$. Utilization of the bundle was 36.2 times higher among the participants who knew about the bundle elements [OR 36.2; 95\% CI 9.98-144; $\mathrm{p}<0.001$ ] as shown in Table 9. 
Table 9. Cross tabulation between utilization and knowledge on the bundle.

\begin{tabular}{|c|c|c|c|c|c|c|c|}
\hline \multirow[t]{2}{*}{ Variable } & \multicolumn{2}{|c|}{ Do you utilize the CAUTI bundle in your unit? } & \multirow{2}{*}{ OR } & \multicolumn{2}{|c|}{$95 \% \mathrm{CI}$} & \multirow{2}{*}{$\begin{array}{l}X^{2} \text { Value } \\
\text { (df) }\end{array}$} & \multirow{2}{*}{$\begin{array}{l}\mathrm{X}^{2} \text { Test } \\
\text { (p-Value) }\end{array}$} \\
\hline & Yes & No & & L.L & U.L & & \\
\hline \multicolumn{8}{|c|}{ Do you know the CAUTI bundle? } \\
\hline No & $4(9.5)$ & $38(90.5)$ & 1.0 & & & & \\
\hline Yes & $38(71.7)$ & $15(28.3)$ & 24.1 & 6.7 & 104 & $36.72(1)$ & $<0.001$ \\
\hline \multicolumn{8}{|c|}{ Are you aware of the elements of the CAUTI bundle? } \\
\hline No & $5(10.2)$ & $44(89.8)$ & 1.0 & & & & \\
\hline Yes & $37(80.4)$ & $9(19.6)$ & 36.2 & 9.98 & 144 & $47.45(1)$ & $<0.001$ \\
\hline
\end{tabular}

Key: LL - Lower Limit, UP - Upper Limit, OR - Odds Ratio, df - degree of freedom, CI - Confidence Interval

\subsubsection{Comparison Between Performance of Audits on the Bundle and its Utilization}

There was a significant association between the performance of audits in the units and the reported utilization of the bundle $\left[\mathrm{X}^{2}(1\right.$, 95) $17.97 \mathrm{P}<0.001]$ as shown in Table 10 .

Table 10. Cross tabulation between performance of audits and bundle utilization.

\begin{tabular}{|c|c|c|c|c|c|}
\hline & \multicolumn{2}{|c|}{ Audits on CAUTI utilization done } & \multirow{2}{*}{$\mathrm{X}^{2}$ Value } & \multirow{2}{*}{ df } & \multirow{2}{*}{$\mathrm{X}^{2}$ test (P value) } \\
\hline & Yes & No & & & \\
\hline \multicolumn{6}{|c|}{ Do you utilize the CAUTI Bundle? } \\
\hline No & $2(3.8)$ & $51(96.2)$ & & & \\
\hline Yes & $16(38.1)$ & $26(61.9)$ & 17.97 & 1 & $<0.001$ \\
\hline
\end{tabular}

Key: LL - Lower Limit, UP - Upper Limit, df - degree of freedom

\subsection{Correlation Between the Reported and Observed Bundle Utilization}

\section{Pearson's Correlation coefficient}

Pearson's correlation was used to determine the relationship between the observed and reported utilization of the bundle. There was a weak correlation between the observed and reported utilization of the CAUTI bundle $[r=0.043 ; 95 \%$ CI $0.16-0.24 ; \mathrm{P}=$ $0.678]$ as shown in Table 11.

Table 11. Pearson's Correlation Coefficient of bundle utilization.

\begin{tabular}{llll}
\hline & & Reported & Observed \\
\hline Reported & Pearson Correlation & 1 & $\mathbf{0 . 0 4 3}$ \\
& P- value & & 0.678 \\
Observed & $\mathrm{n}$ & 95 & 95 \\
& Pearson Correlation & $\mathbf{0 . 0 4 3}$ & 1 \\
& P -value & 0.678 & 95 \\
\hline
\end{tabular}

\subsection{Challenges of Utilization of the Care Bundle}

The participants were asked the extent of agreement on various challenges by use of a five Likert scale. The responses are presented in Table 12. Most participants agreed that the challenges affected their level of practice on utilization of the care bundle.

Table 12. Challenges on utilization of the care bundle.

\begin{tabular}{|c|c|c|c|c|c|}
\hline Challenge & SA \% (n) & A \% (n) & U\% (n) & D \% (n) & SD \% (n) \\
\hline Equipment & $37.9(36)$ & $34.7(33)$ & $2.1(2)$ & $15.8(15)$ & $9.5(9)$ \\
\hline Supplies & $34.7(33)$ & $35.8(34)$ & $5.3(5)$ & $14.7(14)$ & $9.5(9)$ \\
\hline Staffing & $33.7(32)$ & $35.8(34)$ & $6.3(6)$ & $14.7(14)$ & $9.5(9)$ \\
\hline Workload & $37.9(36)$ & $37.9(36)$ & $4.2(4)$ & $11.6(11)$ & $8.4(8)$ \\
\hline Lack of infection prevention surveillance & $32.6(31)$ & $40(38)$ & $20(19)$ & $0(0)$ & $7.4(7)$ \\
\hline No audits on CAUTI prevention care bundle & $29.5(28)$ & $48.4(46)$ & $4.2(4)$ & $14.7(14)$ & $3.2(3)$ \\
\hline Presence of active resistors to change within the unit & $27.4(22)$ & $25.3(26)$ & $10.5(10)$ & $28.4(27)$ & $8.4(8)$ \\
\hline
\end{tabular}

\section{Discussion}

\section{Utilization of the CAUTI Bundle}

The participants utilized the bundle although some elements were better utilized more than others. Those that were highly utilized by more than $80 \%$ (76) of the participants were maintaining an intact tamper evident seal, preventing the drainage bag from touching the floor and being overfilled. The other elements were utilized by less than $50 \%$ (48) of the participants. These were preventing obstruction of the urinary 
flow, daily meatal care, hand hygiene, emptying the urine drainage bags and securing the catheter.

Catheter care should always be practiced while taking care of patients. Nurses should ensure that urine drainage bags are not touching the floor and overfilled. It was noted that the study participants utilized these components which were similar to a study by Thompson et al 2010. In their study, $88 \%$ of the participants ensured that the drainage bags were not touching the floor. The drainage bags should be emptied regularly since when they are overfilled they cause traction to the urethral meatus predisposing patients to inflammation and eventually CAUTIs. Although most of the nurses utilized this element, it was contrary to a study by Thompson et al 2010 who had $100 \%$ utilization of the bundle by the participants [34].

Urine is an excellent culture medium for microorganisms hence catheters need to be secured to prevent urine backflow and maintain an unobstructed urinary flow. A low percentage of the nurses $(2.1 \%)$ ensured that the catheters were secured which correlated with a study conducted by Siegel et al 2006 who had a finding of $4.4 \%$ participants utilizing this element [35]. Appah et al 2010 had findings that were closely similar to this study in which only $18 \%$ of their participants secured the catheters [36]. However some studies indicate higher utilization of this element. A study by Shum et al 2016 had $100 \%$ utilization of the bundle as well as Thompson et al 2010 in whose study $94 \%$ of the participants utilized this element of the bundle. There should be maintenance of an unobstructed urinary flow in the catheter drainage system and prevention of loop dependent. It was established that $44.2 \%$ (42) of the nurses utilized this element which was contrary to a study by Thompson et al 2010 who found out that only $18 \%$ of the participants utilized the bundle. It was observed that the most of the participants did not secure the catheters hence there were loop dependents obstructing urinary flow which may have contributed to the low level of utilization of these elements. This was attributed to absence of catheter securement devices. The urinary drainage bag should be emptied with a separate container for each patient. It was noted that the participants used a single container to empty urine drainage bags of two or more patients. It was also observed that there were few urine jugs in these units. This puts the patients at risk of cross infection of microorganisms that cause CAUTIs. The drainage bag should be emptied regularly as a separate procedure into a clean container for each patient [31]. The participants reported to be having challenges of equipment and supplies which was attributed to the low utilization of the bundle.

Meatal care should be performed at least daily and after bowel incontinence with soap and water. The findings from this study were in congruent with those of Fink et al 2010 in whose study $43 \%$ of the respondents performed meatal care as per the guidelines. This may be related to the fact that the nurses had a lot of workload impeding utilization of the bundle element. It was noted that the respondents were actually performing meatal care only once when they provided care especially when they were rendering baths.
However, it was noted that the nurses only changed the patients without performing meatal care when they had fecal incontinence. This was contrary to the recommendations of which catheter hygiene and meatal care should be performed daily and after any episode of incontinence or bowel movement [37]. In a randomized study by Koskeroglu et al 2004, there was no benefit in using antiseptics for perineal care on prevention and decreasing the rate of CAUTI. The participants who reported to be using antiseptic for meatal care $45 \%$ of the participants reported to using antiseptics for meatal care. Utilization of hand hygiene practice is important in preventing CAUTIs. It was observed that the participants wore gloves without first washing hands and there was an increase in hand hygiene post removal of gloves. This was similar to a study by Ghorbani et al 2016 in whose study hand hygiene compliance was poor among the critical care nurses before wearing gloves $(14.8 \%)$ and that they wore gloves without washing hands. Contrary to these findings, a study by Fikah et al 2010 had $89 \%$ of the participants maintaining hand hygiene. The participants' lack of adequate utilization of hand hygiene in this study was attributed to the fact that there was inadequate supplies that hindered utilization of this element. It was observed that there were times when there was no hand towels for drying the hands hence the participants tended to shy away from this practice.

\section{Adherence of nurses to the CAUTI Bundle}

The participants' adherence to the bundle was at $49.5 \%$ $(\mathrm{P}>0.05)$ which was similar to a study by Amine et al 2014 in which the adherence level was at $40 \%(\mathrm{P}=0.04)$. These findings were contrary to that by Davis et al 2014 in whose study $90 \%(\mathrm{P}<0.05)$ of the participants adhered to the bundle. Adherence to the bundle decreases transmission of infections as well as CAUTIs. Several studies have shown limited adherence to the bundle at $43 \%$ to $89 \%$ universally as reported by the CDC. This study's adherence level is within this range though the IHI has a guideline of adherence being at $95 \%$ and above to indicate full adherence to the bundle [5, 28]. There was no significant association between adherence to the bundle and the participants' demographic characteristics $(\mathrm{P}>0.05)$ in this study. This indicated that the demographic characteristics did not influence adherence to the bundle. Self-reported adherence was higher than that from observation. No nurse adhered to all the elements of the bundle completely over the study period since the utilization was higher with the first encounter during observation and decreased with the subsequent encounters.

\section{Correlation of the Observed with the Reported Practices} on CAUTI Prevention Care Bundle

There is a weak correlation $(\mathrm{r}=0.043 ; \mathrm{P}=0.678)$ between the observed and reported utilization of the CAUTI bundle. This implied that most of the participants did not utilize the bundle and was contrary to a study by Amine et al in which there was a statistically significant strong negative correlation $(\mathrm{r}=-0.828 ; \mathrm{P}=0.04)$. This suggested their strong role in the prevention of CAUTIs hence, they should become part of a culture of patient safety [23]. The null hypothesis was therefore rejected. It was concluded that there was a 
difference between the observed and reported practices related to utilization of the CAUTI bundle at KNH's CCUs.

Most of the participants reported to be utilizing the bundle which was contrary to the observations that were made during the study. This was attributed to the fact that the respondents reported challenges related to utilization of the bundle. The challenges that were most reported by the participants were supplies, equipment, staffing, workload and absence of continuing medical education within the units. These challenges were also observed during the study period. It was noted that there were few urine jugs used for emptying the drainage bags. The participants practiced hand hygiene but most of the times there were no hand towels to use for drying the hands. There was a high nurse to patient ratio of 2 : 3 as opposed to the guideline of $1: 1$. Nurse staffing and workload has been implicated in the spread of CAUTIs. This was in congruent with a study conducted by Limiotti who found a significant association between patient to nurse ratio and urinary tract infections at $0.86(\mathrm{P}=0.02)$. Heavier workload contributes to poor utilization and adherence to the bundle and higher staffing is associated with a $30 \%$ reduction in CAUTIs. Approximately $27 \%$ of these CAUTIs can be eliminated if the nurse to patient ratios are maintained at adequate levels [38].

\section{Conclusion, Recommendations and Areas of Further Research}

\subsection{Conclusion}

The nurses working in the critical care units utilized the CAUTI bundle elements. The nurses working in the critical care units adhered to the CAUTI bundle while caring for catheterized patients. There was a weak correlation between the observed and reported utilization of the CAUTI bundle. The challenges which hindered utilization and adherence to the bundle were resources, resistance to change, lack of audits, continuing medical education and standardized way of practice that is standard operating procedures, checklist.

\subsection{Recommendations}

There is need for continuous medical education on CAUTI bundle within the critical care units. In the CCU there is need for formulation of standard operating procedures and checklist to be used in the standardization of nursing care related to utilization of the bundle. There is need for clinical audits and reaudits to help inform and guide the healthcare providers, managers and policy makers in drafting evidence based policies on CAUTI bundle. The management should provide the nurses with enough resources to enable them utilize the CAUTI bundle.

\subsection{Areas of Further Research}

Studies in different settings to include other institutions both public and private, study design and incorporate other components such as the insertion bundle as well as the culture of nursing practice preventing the transfer of knowledge to practice.

\section{References}

[1] CDC. "Centre of Disease Control Catheter-associated Urinary Tract Infection Guideline Fast Facts." 2015. https://www.cdc.gov/HAI/ca uti/uti.html. [Accesed on 20/03/2016].

[2] Weber D. J, Sickbert-Bennet E E., Gould C. V, Brown V. M, Huslage K, Rutula W. A., "Incidence of catheter-associated urinary tract infections in a healthcare system". Infect control hosp Epidemiol., 2011; 32 (8): 822-823.

[3] CDC, "Diagnosis, Prevention and Treatment of CatheterAssociated Urinary Tract Infection in Adults". 2009 International Clinical Practice Guidelines from Infectious Diseases Society of America. 2009.

https://www.google.com/webhp?sourceid=chromeinstant\&ion $=1 \&$ espv $=2 \&$ ie $=$ UTF $8 \# q=$ Diagnosis $\% 2 C+$ Prevention + and $+\operatorname{Tr}$ eatment + of + Catheter-

Associated+Urinary+Tract+Infection+in+Adults. [Accessed on 10/03/2016].

[4] Saint S, Olmstead R. N, Fakih M. G, Watson S. R, Sales A. E \& Krein S. L, "Translating health care-associated urinary tract infection research into practice via bladder bundle". Joint commission Qual Patient Saf, 2009; 35 (9): 449-455.

[5] Reser R, Griffin F. A, Haraden C \& Nolan T. W, "Using care bundles to improve health care quality. IHI Innovation series white paper."

http://www.ihi.org/resources/pages/ihiwhitepapers/usingcareb undles.aspx [Accessed on 01/01/2016].

[6] Horner K. L, "Closing the Quality Gap: Prevention of Healthcare Associated Infections."

http://effectivehealthcare.ahrq.gov/index.cfm/search-forguides-reviews-and-

reports/?pageaction $=$ displayproduct\&productid $=738$

[Accessed on 10/04/2016].

[7] Leblebicioglu H., Ersoz G, Rosenthal D. V, Nevzat-Yalcin A, Akan A. O, Sirmatel K. A et al, "Impact of a multidimensional infection control approach on Catheter Associated Urinary Tract Infection rates in adult Intensive Care Units in 10 cities of Turkey." Am J Infect Cont, 2013; 41 (10): 853-891.

[8] Gould C. V, Ulmscheid C. A, Agarwal R. K, Kuntz G and Pegues D. A, "Guideline for prevention of CatheterAssociated Urinary Tract Infections," Infect Contr Hosp Epidemiol, 2010; 31 (4): 391-326.

[9] Clarke K, Tong D, Pan Y, Easley K. A, Norrick B, Ko C, Wang A et al, "Reduction in Catheter-Associated Urinary Tract Infections by bundling interventions". Int J Qual Health Care, 2013; 25 (1): 43-49.

[10] Maturi P. M., "The prevalence of Nosocomial Urinary Tract Infections in patients with indweling urinary catheters at Kenyatta National Hospital". UoN Digital Repository. 2010. http://hdl.handle.net/11295/25007. [Accessed on 3/03/2016].

[11] Inyama H. K, Revathi G, Musandu $J$ and Odero T, "The incidence of Nosocomial Urinary Tract Infections: Kenyatta National Hospital Intensive Care Unit". BIRJ, 2011; 1 (2): 1221. 
[12] Gould C. V, Ulmscheid C. A, Agarwal R. K et al., "Guideline for prevention of Catheter Associated Urinary Tract Infections 2009", HICPAC. 2010.

https://www.cdc.gov/hicpac/cauti/001_cauti.html [Accessed on $3 / 3 / 2016]$.

[13] Ulmscheid C. A, M.itchel M. D, Doshi J. A, Agarwal R, Brennan P. J and Williams K, "Estimating the proportion of Healthcare Associated Infections thatt are reasonably preventable and the related mortality and costs." Infect Contr Hosp Epidem, 2011; 32 (2): 101-104.

[14] Meddings J, Krein S. L, Fikah M. G, Olmsted R. N, Saint S, "Reducing Unnecessary Urinary Catheter Use and other Strategies to Prevent Catheter Associated Urinary Tract Infection: Intergrative Review." BMJ Qual Saf, 2013; 1 (1): 1-5.

[15] IHI "How-to-Guide: Prevent Catheter Associated Urinary Tract Infections. Institute for Healthcare Improvement.." http://www.ihi.org/resources/pages/tools/howtoguidepreventca theterassociatedurinarytractinfection.aspx [Accessed on $14 / 03 / 20167$.

[16] Drenkoja D. M, Kuskowski M. A \& Johnson J. R, "Internet survey of foley catheter practices and knowledge among Minessota nurses." Am J Infect Contr, 2010; 38 (1): 31-37.

[17] Brunett K. P, Erickson D, Hunt A, Beaulieu L, Bobo P \& Shute $\mathrm{P}$, "Strategies to prevent urinary tract infections from urinary catheter insertion in the emergency department." $J$ Emerg Nurs, 2010; 36 (6): 546-550.

[18] Dingwall L \& Mc.Lafferty E, "Nurses' Perception of Indwelling Urinary Catheters in Older People." Nurs Stand, 2010; 21 (16): 35-42

[19] APIC. "Association for Proffessionals in Infection Control and Epidemiology." 2008. http://www.apic.org [Accessed on 20/02/2016].

[20] Ribby K. J, "Decreasing urinary tract infections through staff development, outcomes, and nursing process." J Nurs Care Qual, 2006; 21(3): 272-276. www.ncbi.nlm.nih.gov [Accesd on $20 / 02 / 2016]$.

[21] Blanck A.W, Donahue M., Brenhinger L, Stinger D. K \& Polito C, "A quasi-experimental study to test a prevention bundle for Catheter-Associated Urinary Tract Infections." $J$ Hosp Admin. 2014; 3(4): 101-108. www.sciedu.caljha [Accessed on 20/02/2016].

[22] CDC, "Appendices of guideline for prevention of Catheter Associated Urinary Tract Infections." CDC. 2009. https://www.cdc.gov/hicpac/cauti/001_cauti.html] [Accessed on $20 / 02 / 2016]$.

[23] Amine A. E, Bakr W. M \& Helal M. O. "Evaluation of an intervention program to prevent Hospital-Acquired CatheterAssociated Urinary Tract Infections in an Intensive Care Unit in a rural Egypt hospital." GMS Hyg Infect Control, 2014; 9 (2): 15 . http://www.ncbi.nlm.nih.gov/pubmed/25152860 [Accessed on 22/12/2015].

[24] WHO. "World Health Organization's Patient Safety: WHO Guidelines on Hand Hygiene in Healthcare." First Global Patient Challenge Clean is Safer Care. Geneva. 2009. Available: http://www.who.int. [Accessed on 20/12/2015].
[25] Gould.C. V, Ulmscheid C. A, Agarwal R. K andKuntz G, "Guideline for prevention of Catheter Associated Urinary Tract Infections 2009." Healthcare Infection Control Practices Advisory Comittee. https://www.cdc.gov/hicpac/pdf/CAUTI/CAUTIguideline200 9final.pdf [Accessed on 10/03/2016].

[26] Maki D. G and Tambyah P. A, "Engineering out the risk for infection with urinary catheters." Emerg Infect Dis, 2001; 7 (2): $324-327$.

[27] Titsworth W. L, Hester J, Correia T, Reed R, Williams M et al., "Reduction of Catheter-Associated Urinary Tract Infections among patients in a neurosurgical Intensive Care Unit: a single institution's success." J Nurs. 2012; 116 (4): 911 - 920.

[28] CDC, "Centre of Disease Control: Catheter Associated Urinary Tract Infection Guideline." Fast facts. 2015. https://www.cdc.gov/HAI/ca_uti/cauti_faqs.html. [Accessed on $30 / 03 / 2016$.].

[29] Hanchett M, "Techniques for Stabilizing Urinary Catheters." Am J Nurs. 2002; 102 (3): 44-48.

[30] Crouzet J, Bertrand X., Venier A. B, Badoz M, Husson L \& Talm D, "Control of the duration of Urinary Catheterization: Impact on Catheter Associated Urinary Tract Infections." $J$ Hosp Infect, 2007; 67 (3): 253-257.

[31] CDC, "Appendices of guideline for prevention of catheterassociated urinary tract infections." 2009. Available: http://www.cdc.com. [Accessed on 05/02/2016.].

[32] Gould C. V, Ulmscheid C. A, Agarwal M. D, Kuntz G and Pengues D. A, "Guideline for prevention of Catheter Associated Urinary Tract Infections." Healthcare Infection control Practices Advisory Committee. Infct Contr Hosp Epid., 2010; 31 (4): 319-326.

[33] Dimick G, "Quality Check: An overview of Quality Measures and their Uses." $J$ AHIMA, 2010; 81 (8): 34-38. http://library.ahima.org/doc?oid=101998.[Accessed on 21/01/2016].

[34] Thompson D, Chairez D, Nimmo V \& Scott K, "Point Prevalence Surveillance of foley catheter maintenance and utilization." Foley Catheter Observation Survey. 2016; 2 (3): $12-18$

[35] Siegel T. J, "Do Registered nurses perceive the anchoring of indwelling Urinary catheters as a necessary aspect of nursing care? A pilot study." J Wound Ostomy Continence Nurs, 2006; 33 (2): 140-144.

[36] Appah Y, Hunter K. F \& Moore K. N, "Securement of the Indwelling Urinary Catheter: A Prevalence Study." $J$ Wound Ostomy Continence Nurs, 2016; 43 (2): 173-177. 2016.

[37] Clarke K., Tong D, Pan Y, Easley K. A, Norrick B, Ko C and Wang A. "Reduction in Catheter-Associated Urinary Tract Infections by bundling interventions." Int J Qual Health Care, 2013; 25 (1): 43-49.

[38] Mangnall J \& Watterson L, "Principles of Aseptic Tecchnique in Urinary Catheterization." Nurs Stand, 2006; 21 (1): 49-56. 